\title{
MOTIF BATIK BETAWI SEBAGAI INSPIRASI DALAM DESAIN POSTER PERIBAHASA INDONESIA
}

\author{
Arif Priyono Susilo Ahmad ${ }^{1 *}$, Rina Kartika ${ }^{2}$, dan Hastjarjo Boedi Wibowo \\ ${ }^{1,2,3}$ Desain Komunikasi Visual, School of Design, Binus University \\ Diterima: 23 Desember 2018 / Disetujui: 4 Maret 2019
}

\begin{abstract}
Knowledge, understanding and appreciation of the declining community towards the existence of Indonesian local culture can weaken nationalism's feelings and values. This study looked at a number of things at the same time related to the problem, Indonesian as one of the symbols of nationalism, Betawi batik motifs as one form of unique visual cultural artifacts, and poster design as a medium of visual communication. The purpose of this study is to re-create a sense of belonging and pride in Indonesian culture through the design of Indonesian proverb posters inspired by local visual culture artifacts. This research was conducted using the stages of the Design Method process that emphasized the process of observation, problem identification, visual concept development, and design implementation. Betawi batik motifs were chosen as a source of inspiration and exploration of Indonesian proverb poster designs that are characterized by Betawi culture. The results of this study are the concepts and design patterns of Indonesian proverb posters inspired by Betawi batik motifs that have strong local characters.
\end{abstract}

Keywords: batik ornament, Betawi, poster design, proverb

\begin{abstract}
ABSTRAK
Pengetahuan, pemahaman dan apresiasi masyarakat yang semakin menurun terhadap keberadaan budaya lokal Indonesia dapat melemahkan rasa dan nilai-nilai nasionalisme. Penelitian ini memandang beberapa hal sekaligus terkait masalah tersebut, bahasa Indonesia sebagai salah satu simbol nasionalisme, motif batik Betawi sebagai salah satu bentuk artefak budaya visual yang unik, dan desain poster sebagai media komunikasi visual. Tujuan penelitian ini adalah merajut kembali rasa memiliki dan bangga terhadap budaya Indonesia melalui desain poster peribahasa Indonesia yang terispirasi dari artefak-artefak budaya visual lokal. Penelitian ini dilakukan dengan menggunakan tahapan proses The Design Method yang menekankan proses observasi, identifikasi masalah, pengembangan konsep visual, dan implementasi desain. Motif batik Betawi dipilih sebagai sumber inspirasi dan eksplorasi karya desain poster peribahasa Indonesia yang berkarakter budaya betawi. Hasil dari penelitian ini adalah konsep dan pola rancangan poster peribahasa Indonesia yang terispirasi dari motif batik Betawi yang memiliki karakter lokal yang kuat.
\end{abstract}

Kata Kunci: motif batik, Betawi, desain poster, peribahasa

\section{PENDAHULUAN}

\section{a. Latar Belakang}

Saat ini masyarakat semakin akrab dengan artefak-artefak budaya visual yang diimpor dari negara lain, dan sebaliknya, generasi muda semakin lemah dalam mengapresiasi budaya lokal yang sangat kaya. Menurut Sachari (2007), budaya visual adalah tautan wujud kebudayaan konsep (nilai) dan kebudayaan materi (benda) yang dapat ditangkap oleh indra visual (mata), dan dapat dipahami sebagai model pikiran manusia untuk meningkatkan kualitas hidupnya. Representasinya dapat berupa seni rupa, desain, arsitektur, film, multimedia, seni pertunjukan, fashion, gaya hidup, hingga komik picisan. Budaya visual popular telah mendominasi kehidupan masyarakat, dari yang tinggal di gedunggedung di perkotaan hingga ke pedesaan.

*email: arifpsusilo@gmail.com 
Teknologi telepon pintar

(smartphone) semakin mendominasi pikiran dan laku para penggunanya, dan tentu saja mempengaruhi hasrat, mimpi, dan perilaku dalam keseharian mereka. Melalui internet dan telepon pintar (smartphone), dunia terasa lebih kecil dan segala fasilitas dapat dijangkau dengan mudah dan segera. Kemudahan dan kecepatan menjangkau jarak tersebut menjadikan segala sesuatunya tampil simpang siur. Hal-hal baik, tabu, kebenaran, dan kepalsuan tidak jelas terlihat, karena semua ditampilkan sebaik-baiknya. Dunia digital yang hadir dalam genggaman tangan itu sekaligus telah menciptakan dunia nirbatas (borderless world) yang ambigu. Bahkan sering kali dengan mudahnya dapat menghilangkan sifat-sifat sosial manusia. Sifat-sifat yang memuliakan, hormat, santun, dan bangga pada nilai-nilai luhur dapat dengan segera beralih pada nilai keburukan. Dalam ranah budaya, generasi muda lebih banyak mengenal dan mengagumi budaya popular dari negara lain. Budaya leluhur dalam bentuk tradisi yang memiliki nilai-nilai luhur dan spiritual justru banyak ditinggalkan oleh generasi muda.

Salah satu identitas bangsa Indonesia yang dibanggakan adalah bahasa Indonesia. Bahasa Indonesia telah banyak berkembang dan dipelajari di sekolah-sekolah tingkat dasar hingga perguruan tinggi. Semakin terbukanya kran globalisasi, sebagian masyarakat memperlakukan bahasa Indonesia berkembang menjadi bahasa pergaulan non formal. Beberapa di antaranya membuat plesetan dari bahasa Indonesia baku. Di sisi lain, Indonesia memiliki peribahasa yang jumlahnya ribuan, dan berasal dari pelosok nusantara. Peribahasa adalah bahasa sastra yang berupa kumpulan kata-kata kiasan yang terdiri dari kalimat ringkas padat, berisi perbandingan, perumpamaan, nasehat, sindiran, prinsip hidup atau aturan tingkah laku. Dalam peribahasa, tersirat unsur sistem budaya masyarakat yang berkaitan dengan nilainilai, pandangan hidup, norma, petunjuk dan aturan yang menjadi acuan bagi anggota masyarakat. Kini, peribahasa tidak banyak dijumpai dalam praktek berkomunikasi, baik formal maupun informal. Keberadaannya banyak terjilid dalam buku-buku pelajaran sekolah. Dalam beberapa kesempatan, poster-poster kata-kata bijak dan poster berisi kata-kata inspirasi atau motivasi dalam bahasa inggris banyak dijumpai.

\section{b. Identifikasi Masalah}

Pengetahuan, pemahaman dan apresiasi masyarakat yang semakin menurun terhadap keberadaan budaya lokal Indonesia dapat melemahkan rasa dan nilai-nilai nasionalisme. Generasi yang tidak apresiatif dan tidak peduli pada budaya sendiri menjadi ancaman serius yang dapat meruntuhkan sendi-sendi kehidupan sebuah bangsa. Penelitian ini penting dilakukan karena sangat sulit menemukan karya desain poster peribahasa Indonesia baik di lingkungan fisik maupun di jagat maya. Beberapa desain poster peribahasa Indonesia dibuat secara asal-asalan dan tidak menunjukkan kualitas artisitik yang baik. Dalam kaitannya sebagai komunitas akademis, penulis memposisikan diri sebagai pihak yang juga bertanggungjawab membangun pemahaman dan mendorong terciptanya karya-karya desain komunikasi visual, khususnya desain poster peribahasa Indonesia yang baik. Penulis yakin bahwa desain poster peribahasa Indonesia yang baik, berkarakter budaya lokal yang kuat dan artisitik dapat menjadi media komunikasi visual yang efektif bagi masyarakat.

\section{c. Tujuan dan Manfaat Penelitian}

Tujuan penelitian ini adalah merajut kembali rasa memiliki dan bangga terhadap budaya Indonesia melalui desain poster peribahasa Indonesia yang terispirasi dari artefak-artefak budaya visual lokal. Desain poster peribahasa Indonesia berkarakter budaya lokal yang kuat dapat membantu menghidupkan nilai-nilai kebaikan dan filosofi yang dikandungnya dan juga dapat membangun motivasi dan inspirasi positif bagi generasi muda.

Nilai-nilai dan rasa kebanggaan terhadap bahasa Indonesia yang salah satunya melalui 
peribahasa Indonesia sangat penting untuk selalu ditumbuh kembangkan. Dengan semakin banyaknya desan poster peribahasa Indonesia dengan tampilan menarik dan kekinian, diharapkan dapat membangkitkan rasa bangga terhadap Indonesia. Desain poster sebagai produk budaya visual popular berpadu dengan nuansa motif batik Betawi akan membantu membangkitkan rasa Indonesia.

Mahasiswa dan pengajar bidang desain komunikasi visual akan mendapatkan pendangan dan pemahaman yang komprehensif mengenai pentingnya eksplorasi desain poster dengan memanfaatkan kekayaan ornamen Indonesia untuk mendukung penyampaian konten atau pesan tertentu kepada audien. Adapun hasil dari penelitian ini adalah konsep dan pola rancangan poster peribahasa Indonesia yang terispirasi dari motif batik Betawi yang memiliki karakter lokal yang kuat. Desain poster dengan pendekatan visual yang modern dan memiliki karakter budaya visual lokal mulai banyak diminati oleh kalangan muda. Desain poster peribahasa Indonesia dapat diimplementasikan pada beragam media atau multi channel, baik sebagai media poster konvensional maupun digital. Keberadaan Desain poster peribahasa Indonesia dengan pola baru akan memperkaya wacana penciptaan desain poster berkarakter local yang unik di Indonesia. Pada tataran yang lebih luas, penelitian ini dapat bermanfaat sebagai cara untuk mendorong terwujudnya pengembangan kualitas karya desain bagi masyarakat khususnya yang mendalami bidang desain komunikasi visual.

\section{METODE PENELITIAN}

Penelitian ini dilakukan dengan menggunakan tahapan proses kreasi The Design Method yang menekankan proses observasi, identifikasi masalah atau isu, pengembangan konsep visual, dan implementasi desain (Karjaluoto, 2014).

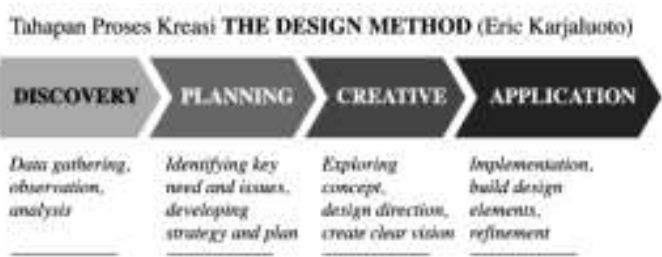

Gambar 1. Tahapan proses penciptaan desain.

Sumber: (Karjaluoto, 2014)

Pada gambar 1, tahapan proses penciptaan desain terbagi menjadi 4 tahapan, yaitu discovery, planning, creative dan application. Pada tahap discovery, akan dilakukan pengumpulan data yang terdiri dari data mengenai motif batik Betawi, baik melalui literatur, internet, kunjungan ke pusat batik, dan wawancara. Setelah melakukan analisa terhadap data yang diperoleh, tahap berikutnya adalah mengidentifikasi kebutuhan dan isu-isu terkait dengan proses perancangan desain poster peribahasa Indonesia tersebut.

Tahap berikutnya adalah creative, dimana dalam tahap ini akan dilakukan eksplorasi konsep kreatif, dan pendekatan visual yang sesuai dengan visi desain poster. Luaran dari tahap ini adalah konsep verbal dan visual. Dan terakhir adalah tahap application, dimana dalam tahap ini, konsep visual yang sudah diperoleh mulai diterapkan dalam desain poster. Pada tahap ini, luaran akhir yang dihasilkan adalah metode atau pola dan rancangan desain poster peribahasa Indonesia dengan pendekatan visual yang terinspirasi dari motif batik Betawi.

Pada tahap visualisasi, proses kreatif merujuk pada prinsip Reconstruction yang dianut oleh Christopher Clark (Lupton, 2014) yang terdiri dari beberapa tahapan, yaitu pengumpulan materi dasar, membuat analisa, mengobservasi data material yang didapatkan, mengkompilasi data temuan, dan terakhir adalah membuat kreasi baru dengan cara merekonstruksi materi awal berdasarkan tahapan sebelumnya. 
Materi utama dalam penelitian ini adalah motif batik Betawi, peribahasa Indonesia yang popular, dan tipografi. Pada tahap pertama, motif betawi akan diseleksi dan dianalisa berdasarkan keunikan bentuk, tingkat popularitas dalam masyarakat, dan makna simbolik yang melekat di dalamnya. Setelah diseleksi, motif tersebut akan dieksplorasi menjadi bentuk-bentuk visual yang lebih sederhana dan ikonik. Bentukbentuk yang ikonik dan sederhana ini dibuat untuk kemudian dipadukan kembali dengan tipografi yang sudah dipilih.

Pemilihan jenis huruf didasarkan pada analisa bentuk yang memiliki dasar estetika yang baik dan karakter yang modern. Huruf dan ikon dari motif batik Betawi yang sudah dihasilkan sebelumnya akan dieksplorasi kembali untuk mendapatkan alternatif bentuk-bentuk baru desain tipografi yang memiliki karakter dan kesan Betawi. Desain tipografi yang dihasilkan akan digunakan dalam proses perancangan desain poster secara menyeluruh untuk mendapatkan kesan kesatuan dalam desain. Desain tipografi dengan karakter baru tersebut digunakan dalam proses perancangan desain poster peribahasa, baik sebagai huruf maupun sebagai elemen desain yang memperkuat karakter desain.

Pada tahap akhir perancangan desain poster peribahasa, peran tipografi menjadi yang paling penting, karena mampu menyampaikan karakter visual dan pesan sesuai dengan isi pesan peribahasa. Proses perancangan tersebut menghasilkan pola desain poster peribahasa yang memiliki karakter visual Betawi sebagai bagian dari rencana perancangan desain poster peribahasa dengan karakter budaya nusantara yang kuat.

\section{HASIL DAN PEMBAHASAN Proses kreasi}

Proses kreasi pada perancangan desain poster peribahasa Indonesia ini dilakukan dengan mengumpulkan data-data visual mengenai motif batik Betawi, memilih, dan melakukan modifikasi bentuk, dari bentuk motif ilustratif menjadi gaya ikonik yang lebih sederhana. Proses kreasi ini menghasilkan kemungkinan-kemungkinan pola pemanfaatan motif batik pada desain poster sebagai berikut:

a. motif batik sebagai latar belakang (background).

Pola ini sangat sederhana, dimana motif batik ditampilkan hanya sebagai latar belakang desain. Tampilan motif akan terlihat besar dan jelas. Pilihan tampilan dapat bervariasi, tergantung pada bagaimana desainer akan menciptakan kesan dan karakter desain terhadap motif yang dipakai.

b. motif batik sebagai bingkai (frame).

Pola ini juga sederhana, dimana motif batik ditampilkan hanya sebagai kerangka desain. Tampilan motif akan terlihat sebagian dari tampilan motif secara keseluruhan. Pilihan tampilan dapat bervariasi, tergantung pada bagaimana desainer akan menciptakan kesan dan karakter desain terhadap motif yang dipakai.

a. motif batik sebagai pengisi huruf (fill in).

Pola ini sangat sederhana, dimana motif batik ditampilkan sebagai pengisi huruf, yaitu memberi variasi dan kesan huruf agar terlihat lebih artistik.

b. modifikasi motif batik dan huruf (type modification).

Pola ini memadukan bentuk motif yang sudah disederhanakan dengan huruf tertentu, sehingga menghasilkan tampilan bentuk huruf yang baru dan bernuansa artistic dengan daya tradisional modern.

c. motif batik sebagai penghias (artisitic ornament).

Pola ini sangat sederhana, dimana motif batik ditampilkan sebagai pendukung desain. Tampilan motif akan terlihat besar dan jelas. Pilihan tampilan dapat bervariasi, tergantung pada bagaimana desainer akan menciptakan kesan dan karakter desain terhadap motif yang dipakai.

\section{Proses desain poster peribahasa}

Objek utama penelitian ini adalah desain poster artisitk, sedangkan peribahasa 
Indonesia berperan sebagai konten, dan eksplorasi motif batik Betawi berperan sebagai elemen visual tradisional. Objektif perancangan adalah memberi inspirasi dan motivasi bagi khalayak sasaran, memperkaya wacana desain poster dengan visualisasi bernuansa budaya nusantara.

Hasil-hasil yang diperoleh dalam penelitian ini berupa konsep dan model perancangan seri desain poster peribahasa Indonesia yang diperuntukkan bagi audien muda berusia anatara 15-21 tahun, khususnya generasi muda yang dinamis, berpandangan terbuka, berpendidikan, dan bersentuhan dengan teknologi digital. Desain poster berukuran $50 \times 70 \mathrm{~cm}$ dapat ditempatkan di ruang kelas, lingkungan dalam sekolah, atau ruang publik. Poster diproduksi dengan teknik digital atau offset.

Perancangan desain poster Peribahasa Indonesia terdiri dari beberapa elemen visual sebagai berikut:

\section{a. Struktur grid}

Elemen grid adalah elemen utama yang berfungsi sebagai struktur dasar komposisi desain poster Peribahasa Indonesia. Susunan grid membentuk karakter dan gaya desain poster. Karakter yang dibangun dalam perancangan desain poster Peribahasa Indonesia ini adalah semi formal dan dinamis. Objek utama berupa teks peribahasa disusun rata tengah (centering) untuk mendapatkan kesan formal, rapi dan jelas. Marjin kiri, kanan, dan atas memberi ruang yang cukup utuk membantu objek utama agar lebih terlihat dominan. Elemen pendukung berupa ornament motif flora disusun diagonal di sebelah kanan atas dan kiri bawah. Elemen tersebut memberikan kesan dinamis pada desain.

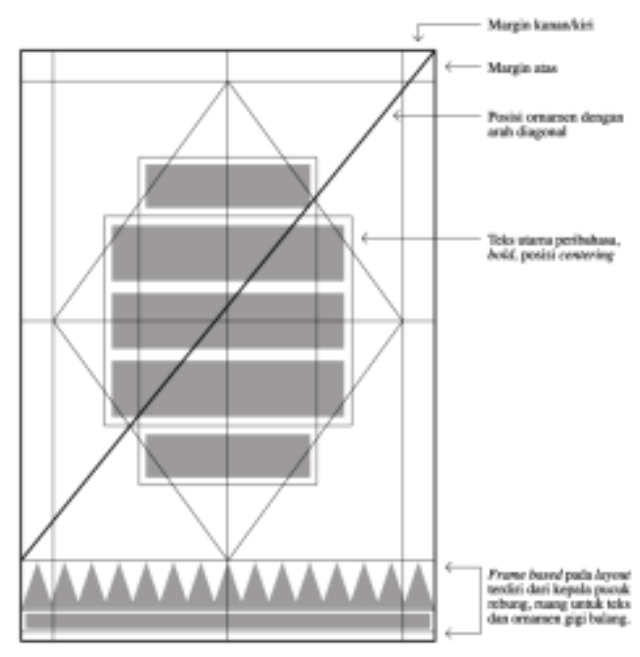

\section{Gambar 21. Struktur grid desain poster peribahsa Indonesia.}

Sumber: penulis

\section{b. Elemen huruf}

Elemen huruf yang digunakan adalah modifikasi dari huruf tipe sans serif dengan elemen motif betawi hasil modifikasi. Jenis huruf sans serif yang memiliki karakter modern yang kuat dan tingkat kemudahan keterbacaaannya yang baik. Pola modifikasi huruf dan elemen ornament dapat dilakukan dengan beberapa teknis, yaitu penggabungan, penambahan atau pengurangan, penggantian dan penggabungan beberapa teknis sekaligus. Hasil dari modifikasi huruf tersebut adalah jenis huruf baru yang dapat dikembangkan secara khusus menjadi jenis huruf Betawi. Huruf adalah elemen desain yang memiliki kesan dan karakter khusus. Huruf dapat membantu mengkomunikasikan pesan tertentu. Dalam studi kasus ini, huruf hasil modifikasi dapat digunakan untuk merancang desain dengan pesan yang positif, gembira, bernuansa tradisional modern, dan atraktif.

\section{c. Elemen ornamen}

Elemen ornamen yang digunakan adalah hasil modifikasi dan stilasi dari motif batik Betawi. Bentuk-bentuk baru tersebut masih menunjukkan karakter dasar bentuk awalnya. Elemen ornamen terdiri dari beberapa macam bentuk flora dan delman. 
Elemen ornamen adalah elemen yang juga penting untuk menggambarkan kesan tradisional modern dalam keseluruhan desain poster.

\section{d. Elemen warna}

Warna yang dipilih adalah warnawarna cerah untuk membantu menciptakan kesan dinamis, gembira, dan optimis. Komposisi warna-warna merah, kuning, oranye, ungu, hijau, dan biru diaplikasikan secara harmonis pada ornamen, huruf dan latar belakang. Warna-warna cerah tersebut diambil dari karakter batik Betawi modern yang popular dengan visualisasi objek-objek popular betawi. Menurut Pratiwi (Kusumowardhani, 2017), corak warnawarna cerah batik Betawi diambil dari warna alam.

\section{Desain akhir poster peribahasa Indonesia}

Pada tahap perancangan Peribahasa Tak ada rotan, akar pun jadi memiliki makna bila tidak ada benda yang bagus, maka apapun dapat dimanfaatkan agar lebih berguna. Makna tersebut menggambarkan sikap positif terhadap suatu keadaan yang terdapat ketidaksempurnaan untuk tidak mudah menyerah. Hal tersebut juga menggambarkan sikap kritis dan kreatif. Kata-kata dalam peribahasa tersebut divisualisasikan dengan komposisi yang semi formal dan dinamis. Kesan dinamis divisualisasikan dengan perpaduan warnawarna cerah yang dominan, komposisi diagonal, dan desain tipografi yang dimodifikasi dengan motif batik Betawi.

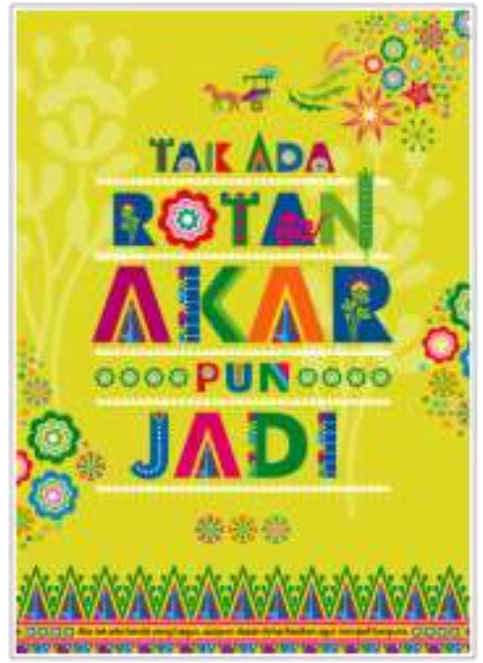

Gambar 3. Tampilan akhir desain poster peribahsa Indonesia dengan warna cerah.

Sumber: penulis

\section{SIMPULAN}

Beberapa hal dapat menjadi simpulan pada penelitian ini:

- Desain poster peribahasa Indonesia dengan gaya desain yang berkarakter budaya betawi memiliki potensi yang besar untuk terus dikembangkan menjadi program khusus pengembangan publikasi peribahasa Indonesia, khususnya bagi dunia pendidikan dasar dan menengah. Desainer dapat bekerjasama dengan ahli budaya tradisi dan lembaga pemerintah, misalnya museum dan departemen pendidikan dan kebudayaan untuk mengelola program tersebut.

- Desain poster peribahasa Indonesia memiliki potensi komersial yang cukup menarik, karena terkait erat dengan fungsi pendidikan dan kebudayaan, khususnya kekayaan budaya lokal. Maka dari itu, setiap karya desain poster dengan karakter dan tema budaya seperti itu harus didaftarkan ke lembaga HAKI.

- Dalam merancang desain dengan pendekatan seni budaya, desainer harus memiliki pemahaman yang baik antara lain terhadap kekayaan budaya visual, dasardasar seni rupa dan desain dan material. 
Pemahaman yang baik mampu menciptakan karakter desain yang unik.

Adapun saran-saran dari penulis adalah sebagai berikut:

- Penelitian dengan objek aktivitas kreatif berbasis budaya visual nusantara di dalam ruang kelas perlu lebih sering dilakukan. Hal tersebut sangat baik karena proses kreatif dalam ruang kelas memiliki kecenderungan yang semakin mengecilkan peran kreativitas yang seharusnya besar.

- Lembaga-lembaga pemerintah dan pendidikan harus lebih banyak menyediakan fasilitas restorasi dan penyimpanan artefakartefak budaya visual nusantara untuk memudahkan para peneliti mendapatkan sumber yang terpercaya.

- Hasil-hasil penelitian seperti ini sebaiknya dipublikasikan dan diseminasikan kepada para pengajar DKV, terutama yang terkait dengan proses kreatif.

\section{DAFTAR PUSTAKA}

Buku

Ambrose/ Harris, Gavin/ Paul. (2011). The Fundamentals of Typography. $2^{\text {nd }}$ Edition. London: Bloomsbury Publishing.

Guntur, (2016). Metode Penelitian Artistik. Cetakan II. Surakarta: Penerbit ISI Press.

Karjaluoto, Eric. (2014). The Design Method: A Philosophy And Process For Functional Visual Communication. United Stated of America: New Rider.

Lupton (editor), Ellen. (2014). Graphic Design Thinking: Beyond Brainstorming. New York: Princeton Architectural Press.

Rohidi, Tjetjep Rohendi. (2011). Metodologi Penelitian Seni. Cetakan ke 10.
Semarang: Penerbit Cipta Prima Nusantara.

Sachari, Agus. (2007). Budaya Visual Indonesia. Jakarta: Penerbit Erlangga.

Saidi, Acep Iwan. (2017). Desain, Media dan Kebudayaan. Cetakan I. Bandung: Penerbit ITB.

Sumarsono, Hartono, dkk. (2017). Batik Betawi. Jakarta: KPG (Kepustakaan Populer Gramedia).

Sunaryo, Aryo. (2009). Ornamen Nusantara: Kajian Khusus Tentang Ornamen Indonesia. Cetakan I. Semarang: Dahara Prize.

\section{Artikel ilmiah}

Casande, Suwito. (2011). Ragam Hias Parang Gerigi Pada Batik Betawi. Jurnal DEIKSIS Volume 03 No. 03, Juli-September 2011

Kusumowardhani, Pratiwi. (2017). Identifikasi Unsur Visual Bentuk dan Warna yang Menjadi Ciri Khas Motif Ragam Hias Batik Betawi Tarogong Jakarta. Seminbar Nasional Seni dan Desain FBS Unesa Jakarta. 28 Oktober 2017

Wijaya, Priscilia Yunita. (1999). Tipografi Dalam Desain Komunikasi Visual. Jurnal NIRMANA Fakultas Seni dan Desain, Universitas Kristen Petra Surabaya, Volume 1 No. 1, Januari 1999

\section{Laman internet}

Latifa, Dina. (2017). Mengenal Sejarah dan Motif Batik Betawi Milik Ibukota. https://saliha.id/fashion/article/1200 8270917-200617-mengenalsejarah-dan-motif-batik-betawi- 
milik-ibukota (diakses 17 Januari 2018)

Muntijo \& Nay. (2016). Peribahasa: Sekilas

Penegrtian, Asal-usul dan

Perkembangannya.

http://pustamun.blogspot.com/2016

/11/peribahasa-sekilas-pengertian-

asal-usul.html (diakses tanggal 17

Januari 2018)

\section{Sumber gambar}

www.potomin2plg.blogspot.co.id

www.disdikbudtebo.org

www.art.pks.id

www.katamami.com

www.brilio.net

www.seracibatikbetawi.wordpress.com

www.adsoftheworld.com

www.designbolts.com 